\title{
ARTIGOS
}

\section{O TRABALHO DE CAMPO COMO EXPERIÊNCIA EDUCATIVA EM GEOGRAFIA}

\section{Linovaldo Miranda Lemos ${ }^{1}$}

Instituto Federal Fluminense

\section{Enviado em 19 mar. 2020 | Aceito em 17 fev. 2021}

Resumo: O presente artigo revisita a temática do trabalho de campo em geografia discutindo aspectos pedagógicos envolvidos na possibilidade de sua implementação, em diferentes níveis. Partindo-se da análise do papel formativo do campo no pensamento geográfico, discute os limites da tradição calcada na pressuposição da neutralidade e da objetividade da observação direta. Contrapõe essa tradição de base positivista às chamadas "epistemologias críticas" que consideram o campo como um "conhecimento situado" sobre processos, pessoas e lugares. Ao reconhecer a importância do trabalho de campo nas práticas da geografia, o artigo objetiva ser uma contribuição ao entendimento do seu papel pedagógico, ressaltando sua capacidade de despertar o interesse pelo aprendizado e, em particular, pelo conhecimento geográfico.

Palavras-Chave: trabalho de campo, ensino de geografia, papel pedagógico.

\section{FIELDWORK AS AN EDUCATIONAL EXPERIENCE IN THE TEACHING AND LEARNING OF GEOGRAPHY}

Abstract: The article reviews fieldwork studies in geography by discussing pedagogical issues involving in the possibility of its implementation. It presents an analysis of the relation between the field and geographic thought, as well as a discussion of the limits of the tradition based on the presumption of neutrality and objectivity in direct observation. The paper opposes this tradition based on positivism to the so-called "critical epistemologies which consider the field as "situated knowledge" of processes, people, and places. By recognizing the importance of fieldwork in geographic practices, this article aims to be a contribution to the understanding of its pedagogical role, highlighting its ability to awaken interest in acquiring the geographic knowledge.

Keywords: fieldwork, geography teaching, pedagogical role.

\section{LE TRAVAIL DE TERRAIN COMME EXPÉRIENCE ÉDUCATIVE DANS LA GÉOGRAPHIE}

Résumé: Cet article revisite le sujet du travail de terrain en géographie en discutant des aspects pédagogiques impliqués dans la possibilité de sa mise en œuvre, à des différents niveaux. En partant de l'analyse du rôle formatif du terrain dans la pensée géographique, il discute les limites de la tradition fondée sur l'hypothèse de la neutralité et de l'objectivité de l'observation directe. II oppose cette tradition fondée sur le positivisme à ce qu'on appelle les "épistémologies critiques" qui considèrent le terrain comme une forme de connaissance située sur les processus, les personnes et les lieux. Toute en reconnaissant l'importance du travail de terrain dans les pratiques de la géographie, l'article se veut une contribution au rôle pédagogique propre du terrain, en mettant en évidence sa capacité à éveiller l'intérêt pour l'apprentissage et, en particulier, pour la connaissance géographique.

Mots-Clé: travail de terrain, enseignement de la géographie, rôle pédagogique.

1. Doutor em Geografia pela Universidade Federal do Rio de Janeiro. Professor da Licenciatura em Geografia do Instituto Federal Fluminense (IFF) - Campus Centro. E-mail: linovaldomlemos@gmail.com. ORCID: https://orcid.org/0000-00025420-7221. 


\section{Introdução}

Há uma convergência entre diferentes abordagens teórico-metodológicas em geografia em se reconhecer a relevância do trabalho de campo, tanto na pesquisa científica quanto na formação de geógrafos e de futuros professores. Sob diferentes roupagens didático-metodológicas, também a geografia escolar the reserve um papel de destaque, como uma poderosa ferramenta voltada ao ensino. Embora não negue que "do ponto de vista de sua função cognitiva, o campo é uma das fábricas do conhecimento geográfico" (LÈVY, LUSSAULT, 2003, p.904), pretendo, no presente artigo, discutir aspectos relacionados à implementação dessa ferramenta.

Ressalto que neste texto discuto o trabalho de campo em geografia dando especial atenção ao seu aspecto pedagógico. Embora procure relacionar o campo ao pensamento geográfico mais amplo, utilizo duas formas de abordar a questão: de um lado, o compromisso com o entendimento do campo como uma possibilidade, dentre muitas, na formação acadêmica de futuros geógrafos e de professores de geografia. De outro lado, detenho minha atenção, também, na discussão sobre a relação entre conhecimentos acadêmicos e conhecimentos escolares e o processo de tratamento didático-pedagógico que estão envolvidos na consecução do propósito educativo do trabalho de campo na geografia escolar.

O texto não pretende ter um caráter prescritivo sobre a maneira de proceder no campo e nem trazer um relato de uma experiência específica. Fundamentalmente, visa contribuir com a discussão do papel que o campo tem na construção do conhecimento geográfico em seu sentido mais amplo (GOLLEDGE, 2002) baseando-se, para isso, em elementos do pensamento geográfico, de forma a compreender: 1) o seu papel na formação de geógrafos; 2) o caráter pedagógico do trabalho de campo e, 3) o tensionamento do trabalho de campo entre práticas e saberes da academia e da escola. Portanto se, por um lado, ressalto a necessidade da valorização dos saberes que o professor constrói no cotidiano de suas práticas (CHARLOT, 2002; AZZI, 2002), por outro, reforço que o campo se constitui num importante momento da formação de estudantes, de diferentes níveis de ensino, o que faz deste uma oportunidade para a construção do conhecimento, vivência e experimentação com vistas à aprendizagem em geografia (HERTAS, 2007; COCATO, 2019).

\section{Trabalho de campo e formação de geógrafos}

Tomemos, como denominador comum para o raciocínio do que vem a ser o trabalho de campo em geografia, a definição fornecida pelo The Dictionary of Human Geography (Derek Gregory et al., 2009, p. 251) de que este é uma maneira de coletar dados por meio do envolvimento e do engajamento direto do pesquisador no mundo material. Trata-se de uma definição muito abrangente que serve ao propósito do seu entendimento como uma espécie de "tipo-ideal" weberiano², tendo em vista que, sob diversos contextos acadêmicos e escolares, dentro da geografia, o trabalho de campo pode relacionar-se, a) ao trabalho realizado por professores fora dos limites institucionais dedicados à observação de paisagens, fenômenos, arranjos espaciais que podem ser materializados em parques, ambientes, museus, unidades de conservação, bairros, cidades, etc. ; b) poderia também confundir-se, em contextos muito específicos, com o que chamaríamos de "estágio remunerado", ou seja, a situação de estudantes colocados juntos às organizações sociais ou governamentais,

\footnotetext{
2 o tipo ideal é "um instrumento que orienta o cientista social em sua busca de conexões causais", ou seja, um "instrumento do qual o cientista se vale para guiar-se na infinitude do real" de forma a permitir a "escolha de certas características do objeto que são relacionados de forma racional, mas que sempre acentuam unilateralmente os traços considerados mais relevantes para sua explicação." (QUINTANEIRO et al. 2000, p.134)
} 
companhias, etc, por um período de tempo, trabalhando como empregado para estes, conforme o caso britânico estudado por Martin Kent (KENT et. al., 1997); c) como a pesquisa - individual ou num grupo - coordenada ou orientada por um professor, que coleta informações diretamente no campo, seguindo parâmetros definidos pelos objetivos, questões e hipóteses da pesquisa; d) como o conjunto de observações, levadas a cabo de forma sistemática e servindo a um propósito investigativo, por um estudante, na sua vivência cotidiana, por exemplo, na vida urbana.

No próprio dicionário encontramos elementos para o entendimento de um pano de fundo do que representa o campo em geografia: de um lado, uma tradição, calcada na corrente filosófica do positivismo, que assume como possível a apreensão das realidades geográficas por meio da observação direta e da neutralização da figura do pesquisador. De outro lado, estudos que, refutando a possibilidade de neutralidade e de objetividade do pesquisador, interpretam o trabalho de campo como um "conhecimento situado" sobre pessoas, processos e lugares (Gregory et al., 2009, p.251). Retornarei a esses pontos mais adiante.

A prática do trabalho de campo está associada à formalização da geografia como ciência entre o final do século XVIII e o início do XIX, especialmente com os trabalhos de Alexandre Von Humboldt e seu esforço por compreender a fisionomia das paisagens por meio da experiência prática da observação (CLAVAL, 2013). Ao longo do Século XIX, para além dessa compreensão da fisionomia das paisagens, o trabalho de campo passa a ter um valor cívico, do conhecimento do terreno, do povo, e do aprendizado da capacidade de leitura de mapas e do fortalecimento do próprio corpo

\begin{abstract}
Para além das questões acadêmicas (...) a prática de campo não serve somente para a formação do espírito, mas também é indispensável para a criança e o adolescente que pretende tornar-se um adulto completo, uma vez que ela assegura o desenvolvimento harmonioso de seu corpo, como enfatiza Elisée Reclus (1866). Ela o leva a conhecer o mundo assim como ele é e ensina-o a se movimentar dentro dele, a tirar partido da organização particular de cada espaço. (CLAVAL, 2013, p.4)
\end{abstract}

Ainda segundo Paul Claval é o trabalho de campo que possibilita a descoberta da geografia regional francesa a partir da série de viagens realizadas por La Blache e por seus discípulos, por exemplo, Lucien Gallois e Emmanuel de Martonne. Graças à forte influência da Escola Francesa no Brasil (SILVA, 2012), tal centralidade do campo também se fez sentir por aqui. Na década de 1940 encontramos no artigo do Prof. Francis Ruellan "Trabalho de Campo nas Pesquisas Originais de Geografia Regional" (RUELLAN, 1944) uma mostra da metodologia de trabalho e de ensino dessa escola baseada na Universidade do Distrito Federal (atual UFRJ) e no Instituto Brasileiro de Geografia e Estatística (IBGE). Trata-se de um texto com claro viés didático, versando sobre questões práticas de organização, estrutura, materiais de trabalho e procedimentos a serem implementados nas chamadas "excursões geográficas" (ou "excursões de pesquisa"). Para o mestre francês o trabalho de campo é um componente da própria formação do pesquisador, momento no qual entra em contato com o treinamento na observação dos "traços essenciais da região" (p. 36), tanto aqueles referentes aos elementos físicos, quanto aos humanos. Neste artigo fica clara sua visão a respeito do papel fundamental da observação e do treinamento, no trabalho de campo, para o geógrafo já que

Só existe geografia de gabinete para o compilador. Para o pesquisador, serve apenas de complemento da investigação no campo que é a fonte viva de toda observação e interpretação nova. Desde a origem da geografia moderna, todos os grandes mestres não seguiram outro método, o único em verdade que pode libertar a produção geográfica do trabalho livresco e do vão palavrório sem base científica e sem nenhuma relação com a vida do Globo. (RUELLAN, 1944, p. 45, grifos meus) 
Tal concepção do papel do campo na formação geográfica também se fez presente na chamada "geografia cultural saueriana". Carl O. Sauer, em discurso proferido num encontro da Associação dos Geógrafos Americanos intitulado "The Education of a Geographer", em 1956, chamava atenção, dentre outras questões, para as habilidades a serem desenvolvidas na formação acadêmica de um futuro geógrafo, o papel a ser dedicado ao seu treinamento nas capacidades de observação e de seleção de elementos relevantes da superfície da terra obtidos no campo. $\mathrm{O}$ autor lamenta o abandono do incentivo à observação no campo que estaria negando aos jovens estudantes a melhor oportunidade para "treinar os olhos" para desenvolver generalizações em geografia. No cerne da "educação do geógrafo", Sauer defendia

Underlying what I am trying to say is the conviction that geography is first of all knowledge gained by observation [...]. In other words, the principal training of the geographer should come, wherever possible, by doing field work. (SAUER, 1956, p. 295-296)

A "revolução quantitativa" dos anos 1950 continuou tendo na observação um elemento central, só que agora eram "observações feitas por outros", mudando-se a pesquisa geográfica "do campo para o gabinete" com o levantamento e o tratamento de dados empíricos dispostos em compêndios censitários ou sinopses quantitativas em geral (Derek Gregory et al., 2009, p. 559). Movimento similar a esse ocorreu no Brasil, com o campo sendo secundarizado pelo uso das tecnologias da informação e os modelos matemáticos na voga da geografia "teorética-quantitativa" (ALENTEJANO, ROCHALEÃO, 2006, p. 55).

No que se refere à geografia crítica, há que se ressaltar a importância do artigo de Yves Lacoste "A pesquisa e o trabalho de campo: um problema político para os pesquisadores, estudantes e cidadãos" originalmente publicado na Revista Hérodote em 1977. Neste artigo o geógrafo francês se propõe a discutir problemas éticos e políticos envolvidos na realização do trabalho de campo. Chama a atenção para a postura do pesquisador diante dos "homens e mulheres que ele estuda e cujo território analisa" (LACOSTE, 2006 [1977], p. 77), no que se refere ao seu compromisso ético de comunicar, de apresentar os resultados da pesquisa ao grupo pesquisado. Isso não só para confrontar esses resultados com aqueles que foram objeto de estudo, mas também, para possibilitar transformar esse conhecimento em poder. Há, nesse sentido, uma dimensão política da pesquisa de campo que se refere ao conhecimento partilhado e discutido que se transforma em ferramenta de modificação de realidades. Neste artigo citado, Lacoste faz uma distinção entre o conhecimento que é compilado de fontes oficiais daquele que são produzidos

\footnotetext{
em um país como a França, a proporção de pessoas que fez estudos superiores não é negligenciável, mas a maior parte delas jamais fez um trabalho de pesquisa de campo, uma verdadeira pesquisa, mesmo se tornaram se professores de História e de Geografia: rigorosamente, sabem apenas compilar os elementos de uma documentação já existente. (LACOSTE, 2006[1977], p. 85, grifos meus)
}

Parece-me que tal relação entre a produção de conhecimento no campo e a utilização de dados oficiais encontra nuances na abordagem defendida por Jean Tricart. em artigo publicado no mesmo número da revista Hérodote. O ponto pacífico, mais uma vez, é a defesa da importância do campo, tanto para a pesquisa quanto para a formação do pesquisador. Da mesma forma que no texto de Lacoste há, também em Tricart, uma preocupação pedagógica relativa às orientações metodológicas e de procedimentos sobre o papel do campo na formação do pesquisador em geografia. No entanto, Tricart incorpora o princípio da dialética não só entre o campo e a experimentação, mas também entre o uso de dados oficiais, estatísticos em geral, e as observações pessoais. É a partir dessa 
dialética do/no trabalho de campo que se torna possível, por parte do geógrafo, a formulação de conceitos, formas de representação e de explicações

\begin{abstract}
A dialética baseada no trabalho de campo é, portanto, um elemento indispensável da percepção objetiva dos dados de base do raciocínio científico; quando ela está ausente, elaboram-se teorias que só têm relações longínquas com a realidade perceptível e que, por esse motivo, não têm qualquer utilidade social, pois não podem orientar a ação [...]. 0 objeto da pedagogia é ajudar os outros (não só os jovens) a utilizar essa dialética, a passar da análise dos dados à formulação de conceitos e às teorias explicativas, além de controlar e ajustar estas teorias ao melhor conhecimento dos fatos. É falso opor uma geografia "teórica" a outra, que seria a ciência do "concreto". Teoria e observação são indissociáveis numa abordagem dialética. Análise e síntese são os dois termos de uma oposição dialética, ambos indissociáveis. (TRICART, 2017 [1977], p. 310 e 311)
\end{abstract}

É a partir das "epistemologias críticas" dos anos 1990 (CLAVAL, 2013), especialmente com as geografias feministas, que as críticas mais contundentes aos pressupostos tradicionais do trabalho de campo são empreendidas. Por englobar uma diversidade de vertentes (JOHNSTON, SIDAWAY,2016), é mais prudente referir-se a 'geografias feministas', no plural, como defende Joseli Maria Silva (2010; 2016). Estas demonstraram o caráter relacional, dialógico, pessoal e intersubjetivo da pesquisa de campo, colocando em xeque os pressupostos do seu caráter neutro. Nesse sentido, tais abordagens criaram/criam uma tensão entre o próprio papel dos agentes desse processo, tanto do pesquisador quanto do pesquisado, na estruturação, nas metodologias, nas motivações e nos próprios resultados do trabalho de campo (ENGLAND, 1994; KATZ, 1994; NAST, 1994; SILVA, 2010; DRIVER, 2000). O local geográfico do pesquisador, seu status social, de gênero, de raça e de classe moldam as questões, a coleta e os resultados da própria pesquisa (SUNDBERG, 2003), o que vai ao encontro da percepção do campo como produtor de um conhecimento situado, como me referi anteriormente citando Gregory et al. (2009).

Nesse mesmo sentido, vale destacar a série de artigos dispostos nos dois números especiais da Geographical Review de 2001 (DELYSER, STARRS, 2001) e os relatos de experiências escritos de forma personalíssima e que colocaram em evidência não só a impossibilidade da imparcialidade na pesquisa como também as "relações de poder, subjetividades e dilemas morais envolvidos no trabalho de campo" (MCSWEENEY, WINKLERPRINS, 2020, p. 1). Importante mencionar o recente número especial da Geographical Review intitulado "Fieldwork in the 2st Century" que, numa tentativa de 'revisitar' a antiga Edição de 2001 dedicada ao tema, traz na Edição de 2020, 18 artigos de geógrafos de diferentes fundamentações teórico-metodológicas, mas que, no conjunto, revelam o interesse renovado pelo tema. Trata-se de artigos que, para além das questões metodológicas, versam sobre aspectos mais práticos do trabalho do pesquisador como as pressões por cortes nos orçamentos, redução do tempo de realização dos trabalhos de campo nas universidades, bem como o avanço atual do uso das tecnologias digitais e mídias sociais no campo. No entanto, muito dos artigos se coadunam àquelas "epistemologias críticas" às quais me referi anteriormente, seguindo Paul Claval, demonstrando o espaço para a 'falha' e o aprendizado com os 'erros' no campo na vida profissional-acadêmica do geógrafo, o espaço para a surpresa e para a humildade por parte do pesquisador (MCSWEENEY, WINKLERPRINS, 2020).

Há, então, limites na objetividade e na neutralidade do trabalho de campo em geografia, o que significa incorporar, nessa equação, dimensões como as subjetividades recíprocas (do pesquisador e do pesquisado), bem como as relações de poder (implícitas ou explícitas), que permeiam o campo. Ao assim procederem, as epistemologias críticas nos fazem repensar a própria relação que nós nutrimos - como geógrafos e como professores de geografia - com essa importante ferramenta de 
aprendizagem e de pesquisa. Em primeiro lugar, corre-se o risco de uma reificação do campo: ao situá-lo, de forma acrítica, pode ser tomado como um fim em si mesmo e, no limite, de incorrer-se naquela concepção positivista de uma realidade imanente e que salta aos olhos do observador, num modelo de ciência baseada num empirismo que "considera que os modelos científicos ou os conceitos teóricos emergem gradualmente dos fatos que são revelados à observação sem qualquer pressuposto" (LEGENDRE, 1994, p.659). Do ponto de vista do trabalho de campo como uma experiência educativa, de seus usos como ferramenta pedagógica, esta ressalva se traduz na expectativa de que a "saída" dos alunos da sala de aula, por si só, seja garantia da aprendizagem.

Ao realizar uma extensa revisão da literatura com base em material produzido na Inglaterra no final dos anos 1990, M. Kent, D.D. Gilbertson e C.O. Hunt (1997) nos fornecem elementos bastante úteis para balizarmos o que estou discutindo aqui: o campo serve a um objetivo de aprendizagem e, nesse sentido, se pressupõe, que haja uma definição clara de uma dada estrutura, um planejamento e o estabelecimento de procedimentos e objetivos a serem alcançados. Para melhor compreensão e visão sintética, o quadro abaixo (Figura 1) organiza as ideias dos autores:

Figura 1 - Estrutura da Experiência de Aprendizagem no campo

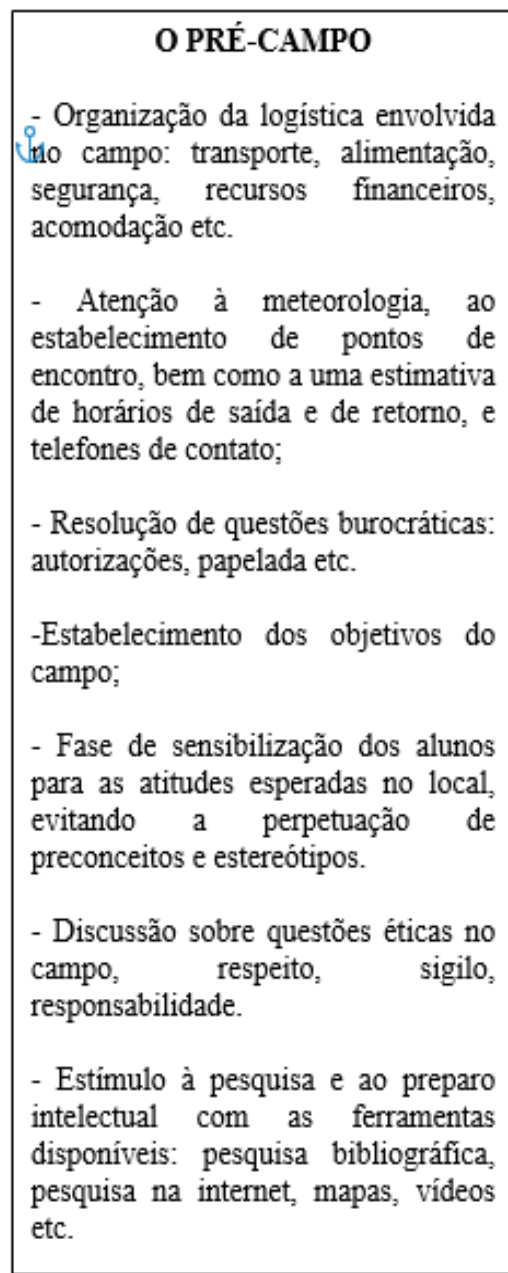

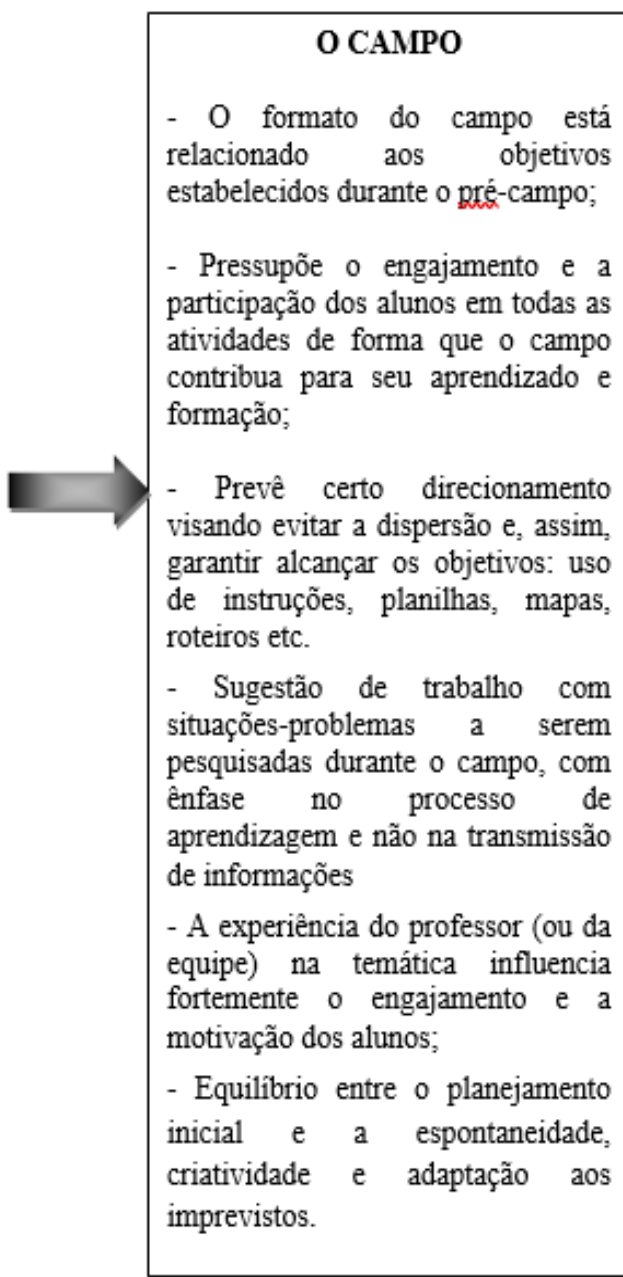

\begin{tabular}{|c|}
\hline $\begin{array}{l}\text { VERIFICAÇÃO DA } \\
\text { APRENDIZAGEM E } \\
\text { TROCA DE EXPERIENCIAS } \\
\text { - É uma retroalimentação } \\
\text { (feedback) em via de mão } \\
\text { dupla: os estudantes informam } \\
\text { ao professor os pontos fortes e } \\
\text { as deficiências da experiência e } \\
\text { o professor faz observações } \\
\text { gerais e analisa casos } \\
\text { especificos; } \\
\text { - Exposição, em grupo, de } \\
\text { impressões, dúvidas, troca de } \\
\text { experiências e sugestões; } \\
\text { - Questionários formais podem } \\
\text { ser realizados bem como a } \\
\text { escrita de relatórios. } \\
\text { Posteriormente pode envolver } \\
\text { algum tipo de avaliação formal; } \\
\text { - Momento de consolidação de } \\
\text { experiências e preparo dos } \\
\text { estudantes para progressão nos } \\
\text { estudos e nas pesquisas; } \\
\text { - Esse momento pode envolver } \\
\text { a discussão dos resultados do } \\
\text { campo em relação aos objetivos } \\
\text { estabelecidos; }\end{array}$ \\
\hline
\end{tabular}


O que está organizado na Figura 01 faz parte, em grande parte, da rotina de formadores de professores e bacharéis em geografia. A fase do pré-campo envolve o planejamento do campo em si, a escolha do local, a estadia, os custos, o transporte etc. Envolve também, para além dessas questões burocráticas e de logística, um preparo dos próprios alunos para a atividade a ser realizada em relação, não só ao estudo prévio, em fontes diversas, como também ao entendimento e respeito ético em relação ao "outro". É nessa fase que se estabelecem os objetivos do campo e a forma como este se coaduna com conteúdo e com temáticas discutidas no curso, com a necessidade de levantamentos de dados, com a verificação de hipóteses e de questões, com o treinamento e a aprendizagem. Enfim, são esses objetivos que justificam o gasto de tempo e de recursos visando atingir certos fins que são pedagógica e cientificamente planejados. No momento do campo propriamente dito, nos deparamos com o equilíbrio entre a participação e o envolvimento dos graduandos e o direcionamento à consecução dos objetivos. Por isso, a proposta de se trabalhar com situações-problema ou de questões desafiadoras a serem "resolvidas" no/por meio do campo. Paralelamente ao campo - e não de forma exclusivamente conseguinte - há a verificação da aprendizagem. Esta não se confunde, de forma estrita, com a escrita de um relatório ou uma prova: é o momento da troca, do diálogo, da consolidação das ideias. O contrário disso é a palestra, a preleção, a exposição que é dada pelo professor responsável, só que fora da sala de aula convencional.

Até que ponto excursões realizadas de ônibus nas quais "os professores, nas diferentes paradas que previram no percurso, fazem um discurso na frente dos estudantes passivos" (LACOSTE: 2006 [1977], p.85), contribui, de forma efetiva, para a construção do conhecimento? Até que ponto, a "pesquisa de campo" realizada com alunos se diferencia de um "passeio turístico"? Ou até que ponto aqueles que saem à pesquisa não se assemelhariam aos que vão a um zoológico ou safári, como repreendeu certa vez Bernar Kaiser (2006, p. 100). Yi-Fu Tuan (2001), na sua vasta experiência com alunos de graduação, nos fornece um relato pessoal a esse respeito. Quantos de nós, professores, não faríamos coro às suas palavras?

My memory of a typical unstructured trip goes something like this. The bus stops on a knoll. Students file out, I among them. Immediately we are bombarded by sensations, from buzzing bees and the smell of hay to the heat of the sun, and images, from garbage dump and church towers to the meandering river. To minimize disorientation and bewilderment we take out our cameras and dramatically reduce the flood of sensations and impressions by looking at a framed landscape through a tiny hole. Our leader, after a brave pause to soak up unstructured experience, proceeds to simplify reality for himself and us by drawing attention to a selection of landmarks. (TUAN, 2000, p. 42)

Nesta seção não pretendi, de forma alguma, proceder a uma análise exaustiva do papel dedicado ao trabalho de campo na perspectiva da geografia enquanto ciência. Pretendi corroborar a ideia da centralidade que este tem nas diferentes abordagens metodológicas e correntes. A partir desses elementos, pretendo, na parte seguinte, discutir mais diretamente a organização, o planejamento e o papel pedagógico do campo na Educação Básica.

\section{O campo como uma ferramenta pedagógica dedicada ao ensino de geografia na Educação Básica}

O reconhecimento da importância do campo extrapola os limites do meio acadêmico e se faz presente, também, na Educação Básica. Nesta, em grande parte, tem-se por pressuposto subjacente que há a necessidade do contato direto do aluno, por meio da experimentação, da pesquisa e de sua interação com seu mundo para que ocorra aprendizagem. Nessa linha de raciocínio, os conceitos espaciais estruturantes da Geografia são construídos a partir da interação do educando com sua 
realidade quotidiana (CAVALCANTI,1998; STRAFORINI, 2004; PÉREZ, 2018) que, por meio de práticas pedagógicas e da estimulação feita de forma consciente e organizada pelo professor, são encorajados e têm a possibilidade de fazer a transformação de conceitos espontâneos (frutos da experiência cotidiana) em conceitos científicos (VYGOTSKY, 1989; 1998).

Dentro e fora do Brasil podemos encontrar exemplos de como o trabalho de campo é reputado como ferramenta importante no processo ensino-aprendizagem. Nos Estados Unidos, o National Council for Geografic Education (NCGE), ao definir no seu site ${ }^{3}$ o que vem a ser a "educação geográfica" considera a geografia como uma matéria ativa, que não pode ser absorvida ou memorizada, mas que, antes de tudo, deve ser estimulada no estudante por meio de atividades para além da sala de aula, ou seja, no campo. O documento "International Charter on Geographical Education" (2016, p.5) ${ }^{4}$ publicado sob os auspícios da "Commission on Geographical Education da International Geographical Union (IGU-CGE)", defende a importância da geografia na compreensão do mundo contemporâneo e na sua capacidade de fornecer habilidades intelectuais e ferramentas de investigação como o uso de sistemas de informação geográfica (GIS), a análise de mapas e o trabalho de campo.

Por aqui a Base Nacional Comum Curricular (BNCC), no seu documento final, destaca para a área de ciências humanas e, particularmente para o componente curricular "geografia", o pressuposto da valorização das "vivências e experiências" dos educandos adquiridas em diferentes contextos, o que faz privilegiar "o trabalho de campo, as entrevistas, a observação, o desenvolvimento de análises e de argumentações, de modo a potencializar descobertas e estimular o pensamento criativo e crítico" (BNCC, 2018, p. 355). Em outras partes, o documento prevê o compromisso da geografia, como componente curricular, no desenvolvimento nos alunos do "espírito de investigação" ou de "práticas e procedimentos de investigação" (p. 366) e arremata afirmando que

Esse processo de aprendizado abre caminhos para práticas de estudo provocadoras e desafiadoras, em situações que estimulem a curiosidade, a reflexão e o protagonismo. Pautadas na observação, nas experiências diretas, no desenvolvimento de variadas formas de expressão, registro e problematização, essas práticas envolvem, especialmente, o trabalho de campo. (BNCC, 2018, p. 369, grifos meus)

A elaboração/organização de um trabalho de campo pode não ser uma tarefa simples para o professor. Do ponto de vista da Educação Básica brasileira, com suas peculiaridades e realidades díspares, há uma série de dificuldades para a realização de atividades como estas em turmas regulares. Além dos problemas relativos à obtenção de recursos financeiros e materiais para a sua realização, o professor tem, ainda, que enfrentar questões burocráticas como a necessária compreensão - e a autorização - de pais, diretores e de sistemas de ensino públicos e privados para a saída da escola. Há, ainda, desestímulos de toda ordem, problemas de (in) disciplina e a preocupação com a segurança dos alunos etc.

De forma geral, pesquisas têm demonstrado que embora haja o reconhecimento da potencialidade do trabalho de campo para o ensino de geografia, este ainda é baseado num modelo centrado na figura do professor e na confiança no sentido da visão/observação. Tal abordagem se dá em detrimento da maior participação do aluno que mobiliza todos seus sentidos, sua emoção e subjetividade no entendimento do mundo (PRESTON, 2016). Para outros autores, no caso específico do Brasil, haveria uma subutilização do trabalho de campo no ensino de geografia na Educação

3 Disponível em: http://ncge.bravesites.com/what-is-geographic-education-. Acessado em: 10 mar. 2020. 4Disponível em https://www.igu-cge.org/wp-content/uploads/2019/03/IGU_2016_eng_ver25Feb2019.pdf. Acessado em 10 mar. 2020 
Básica (COCATO, 2019), muito embora haja múltiplas possibilidades e estratégias de aprendizagens em geografia (SOUZA, CHIAPETTI, 2012) e na sua utilização na pesquisa científica. São exemplos do que estou falando aqui a abertura para antropologia com a utilização do método etnográfico no trabalho de campo nos estudos sobre territorialidades de comunidades tradicionais e de áreas de fronteira (CARNEIRO, et ali., 2013; MAIA, 1997; LOZANO, 2016).

Compiani e Carneiro $(1993)^{5}$ forneceram um valioso instrumental a professores de diferentes níveis na atividade pedagógica envolvendo o trabalho de campo. Os autores propõem parâmetros para o estabelecimento de uma classificação dos "papéis didáticos" das "excursões geológicas". Nesse sentido, o trabalho de campo pode ter caráter, a) ilustrativo, objetivando "mostrar ou reforçar conceitos já vistos em sala" ou "aplicar habilidades adquiridas" (p.94); b) indutivo, feito de forma a "guiar sequencialmente os processos de observação e interpretação" com o estímulo à resolução de problemas (p.94); c) motivador, que estimulam o interesse do aluno para "um dado problema ou aspecto" (p.95) valorizando-se a possibilidade de experiência pessoal no campo e, por fim, e) treinador, com o aprofundamento de habilidades já adquiridas a partir de seu exercício em atividades do/no campo.

Há que se reconhecer, de antemão, o fascínio que o trabalho de campo exerce sobre nós como pesquisadores e professores e, principalmente, sobre alunos em idade escolar. Se a saída dos limites das quatro paredes das Universidades e dos laboratórios representa para estudantes de graduação não só um momento de excitação e alegria como também uma oportunidade de vivência e de crescimento pessoal (VADJUNEC, 2020; HERTAS, 2007), o que dizer de crianças e adolescentes de escolas regulares? Em certos contextos comunitários e escolares, o campo representa o primeiro contato com bens culturais como museus, cinemas, praças, monumentos, bem como com paisagens e lugares. Muitas vezes são situações que, ou não faziam parte das vivências dos alunos ou, talvez, até fizessem parte, mas ainda não haviam sido estimuladas ao exercício distanciamento/aproximação que leva pode levar ao aprendizado. Com o trabalho pedagógico em tais ambientes, os alunos podem ser estimulados a portarem-se diante das suas realidades cotidianas com uma atitude de estranhamento inquisitivo. Nesse sentido, o que chamamos de "trabalho de campo" pode ser traduzido como "passeio" e não há nisto problema algum ou crítica negativa alguma, tendo em vista o que pode significar para a vida do aluno, especialmente para aqueles das escolas públicas que não possuem renda e nem mobilidade na cidade e que encontram na geografia escolar uma oportunidade.

Permito-me reforçar o papel do desejo, da alegria e do envolvimento como um elemento pertinente ao aprendizado. Para Bernard Charlot a relação com o saber se dá por meio de um sujeito em suas confrontações pessoais, ou seja, um sujeito que lida com relações internas. É a partir disso que ocorre o saber (CHARLOT, 2000, p.61). Quem se mobiliza a aprender é um sujeito, isto é, "um ser humano portador de desejos (e levado pelo desejo) e envolvido em relações sociais" (CHARLOT, 2001, p.19). Desejo de saber, levado a cabo por uma pessoa (o aluno) que é mobilizado - ou, talvez, antes, se mobilize - a aprender. Por que evoco tal aparente digressão? Primeiro porque considero que o trabalho de campo realizado com crianças deve ter um caráter pedagógico, mas que, como professores de adolescentes e de jovens, talvez devêssemos ter em mente que nem sempre tudo ocorre de forma reverente como planejamos. Segundo, que o desafio do uso pedagógico do trabalho de campo está, talvez, em mobilizar esses seres-alunos, em toda sua complexidade, uma mobilização em direção à aprendizagem.

50 artigo é baseado na experiência dos autores e na bibliografia sobre o trabalho de campo em geologia, o que não invalida o raciocínio que desenvolvo aqui. 
Para isso não há regras, nem receitas pré-estabelecidas e nem cabe a nenhum pesquisador dizer o que o professor "deve" fazer (muito embora vejamos, a todo instante, artigos com expressões impositivas do tipo "o professor tem que ser criativo" ou "o professor tem que incorporar as novas tecnologias"!). Mais uma vez faço eco ao que pensa Bernard Charlot, em outra obra, sobre o papel da pesquisa em educação:

\footnotetext{
Ser professor é defrontar-se incessantemente com a necessidade de decidir imediatamente o dia-a-dia da sala de aula [...] A pesquisa não pode dar inteligibilidade a todas as mínimas ações da vida do professor em sala de aula [...] acho que ninguém tem o direito de dizer ao professor o que ele deve ser na sala de aula [...] o papel da pesquisa é forjar instrumentos, ferramentas para melhor entender o que está acontecendo em sala de aula; é criar inteligibilidade para melhor entender o que está acontecendo ali. Depois o professor vai se virar, no dia a dia, na situação contextualizada em que estiver vivendo. (CHARLOT, 2002, p.91)
}

O que é possível apontar são algumas experiências e proposições diversas, no âmbito da geografia escolar, na seara do que estou tratando aqui. Rodrigues e Otaviano (2001), baseadas nas suas experiências como professoras, estabelecem algumas "orientações pedagógicas relevantes para a organização de um trabalho de campo" como a definição dos objetivos, a escolha do local com a ida/conhecimento prévio do professor desse ambiente, a preocupação com a escolha do melhor período dentro do calendário escolar, a mobilização de recursos materiais como transporte e material de estudo como folhetos, mapas, panfletos etc., a busca pela interdisciplinaridade e a cooperação e a integração entre a geografia e outras disciplinas (PONTUSCHKA, et.al, 1991).

Como o leitor pôde perceber, optei por evitar qualquer tipo de prescrição para um trabalho de campo que poderíamos considerar eficiente. O quadro apresentado na Figura 01 ocupou o espaço de uma síntese da bibliografia sobre o tema e não uma opção de metodológica a ser transplantada da Universidade para a Educação Básica e isso principalmente porque, embora se tratem de espaços educativos que se comunicam, há especificidades e diferenças. Por isso, na próxima seção, discuto abordagens sobre a difícil tarefa de estabelecer um diálogo entre o conhecimento que adquirimos na universidade, como licenciandos, e nossas práticas como professores da Educação Básica.

\section{Trabalho de campo: entre práticas e saberes da academia e da escola}

Os conhecimentos que recebemos durante os anos na universidade fazem parte do arcabouço teórico-metodológico que serão mobilizados no exercício da nossa profissão como professores. No entanto, esse não é um ato de efetivação imediata e completa, mas sim uma constante construção realizada diante de desafios do dia a dia e que depende de como o "professor compreende a diferença entre a disciplina acadêmica e a disciplina escolar dentro de sua identidade disciplinar através de seu envolvimento com o conteúdo no momento da formação inicial da docência" (BROOKS, 2019, p.146). É no momento de sua prática, em situações concretas diante de uma turma, que emerge o desafio de como mobilizar aqueles conteúdos acadêmicos e torná-los "ensináveis".

O pano de fundo da questão aqui são as possíveis relações e inter-relações entre disciplinas acadêmicas e escolares. Baseada na literatura sobre o tema, Stengel (1997) sumarizou três possibilidades de compreensão dessa relação: a) conhecimentos acadêmicos e conhecimentos escolares são essencialmente contínuos, havendo uma estrutura fundamental de princípios e de métodos das disciplinas (como a matemática) que são apropriados, num grau mais ou menos simplificado, de acordo com o nível acadêmico e/ou escolar; b) disciplinas acadêmicas e disciplinas escolares são descontínuos, o que tanto pode engendrar uma visão simplista de que as disciplinas escolares sejam versões "diluídas", atenuadas, do conhecimento acadêmico ou, num grau de 
sofisticação maior, de que a disciplina escolar é fruto de uma transformação dos conhecimentos prévios, adquiridos na universidade, num conhecimento pedagógico, escolar, dos conteúdos; c) a terceira via interpretativa, baseada nos trabalhos de Jhon Dewey, propõe que disciplinas são diferentes, mas relacionadas de uma forma dialética, ou seja, são inter-relacionadas. Isso não significa negar o suporte do conhecimento disciplinar no trabalho do professor, mas sim reconhecer que a base do seu trabalho se encontra nas diversas vivências dos alunos como seres humanos que se preocupam com eventos do mundo real ${ }^{6}$.

Preliminarmente talvez devêssemos pensar a dinâmica do trabalho de campo mais próxima destes últimos termos, ou seja, conciliando o reconhecimento da importância dos sólidos conhecimentos acadêmicos do campo disciplinar da geografia, enquanto ciência, com as questões, situações e problemas do mundo das vivências cotidianas dos alunos e do próprio ambiente escolar. E isso não no sentido de reforçar o conhecimento empírico, mas sim de transformá-lo por meio do saber pedagógico, aquele que "o professor constrói no cotidiano de sua prática e que fundamenta sua ação docente, ou seja, é o saber que possibilita o professor interagir com seus alunos, na sala de aula, no contexto da escola onde atua (...)" (AZZI, 2002, p.43).

Essa é uma posição que assinalo para pensarmos a respeito da aceitação da reprodução de práticas, às vezes mais e às vezes menos eficazes, oriundos de espaços acadêmicos transplantados para espaços escolares regulares sem a devida preocupação com a mediação desse saber pedagógico. Como nos advertiu Clare Brooks (2019, p. 145) "é muito simplista supor que uma disciplina escolar seja uma versão resumida da disciplina acadêmica".

Quero com isso chamar a atenção para o fato de que, dentro do foco do presente artigo, além da discussão sobre a própria natureza do conhecimento produzido no/pelo trabalho de campo, das questões de método, da natureza da pesquisa e do conhecimento produzido a partir dele, ainda há que se ter em mente e se dar a devida atenção ao fato de que as práticas da Universidade não deveriam ser transplantadas, ipsis litteris, para a Geografia Escolar. Como resultado, ao incorporarmos o campo como uma estratégia pedagógica no trabalho de sala de aula na Educação Básica essas especificidades podem ser levadas em conta.

Ao assim procedermos, ou seja, ao reconhecermos as especificidades dos diferentes níveis e modalidades de ensino, estamos flexibilizando aquela concepção da transposição didática preconizada por Yves Chevallard (2000[1991]). Baseando-se em sua experiência e atuação no campo da didática da matemática este autor defendia o pressuposto de que saberes de referência (ou seja, o conhecimento científico) passavam a serem designados como saberes a serem ensinados (os conteúdos escolares) por meio de um conjunto de adaptações a fim de torná-los passíveis de serem compreendidos na escola. Por mais que houvesse, de forma implícita ou explícita, um esforço de "tradução" didática de conteúdos científicos, há que se reconhecer a pouca margem para a compreensão do papel ativo da escola e a ausência de uma abordagem dialética no que se refere às relações recíprocas entre esta e a academia na questão da produção do conhecimento e das práticas pedagógicas.

Embora esta concepção seja um avanço em relação ao modelo tradicional mnemônico de educação geográfica, ela ainda carrega consigo um risco imbricado na ideia implícita de "transpor" algo de um "lugar para outro, da academia para a escola, "sem alterações" (LOPES, 1999, p. 208). Como dissemos, são dimensões e espaços congruentes, mas, ao mesmo tempo, diferenciados. Entre

6 Em suma, citando textualmente Stengel (1997, p. 599): "There is something objectively important in the substance of the disciplines; however, the disciplines themselves arise out of efforts to understand and unpack the mysteries and challenges of humans living in the world. The moral may be hidden or even mystified, but it is always present just beneath the surface of academic knowledge". 
uma e outra (ou seja, entre o "saber sábio" e o "saber ensinado"), há uma "cadeia de transposição" que é heterogênea e cheia de interposições, traduções, mudanças e transformações, como nos faz pensar Philippe Perrenoud (1998) ${ }^{7}$.

Caminhamos, assim, para uma compreensão da questão, que reconhece a possibilidade de contestação, reorganização, reestruturação pela escola, assumindo um papel ativo diante do próprio currículo e das políticas públicas educacionais (LOPES, 1997; FORQUIN, 1996; MAINARDES,2006). Tendo em vista esse papel ativo da escola e de seus professores, situamos o problema em termos de uma "mediação didática" no seu sentido dialético como defende Lopes (1999)

\begin{abstract}
Mais coerentemente, devemo-nos referir a um processo de mediação didática. Todavia, não no sentido genérico, ação de relacionar duas ou mais coisas, de servir de intermediário ou "ponte", de permitir a passagem de uma coisa a outra. Mas no sentido dialético: um processo de constituição de uma realidade a partir de mediações contraditórias, de relações complexas, não imediatas. Um profundo sentido de dialogia [...] O trabalho de didatização acaba por implicar, necessariamente, uma atividade de produção original. Por conseguinte, devemos recusar a imagem passiva da escola como receptáculo de subprodutos culturais da sociedade. Ao contrário, devemos resgatar e salientar o papel da escola como socializadora / produtora de conhecimentos. (LOPES, 1999, p.208-209 e 218)
\end{abstract}

Tendo em mente o trabalho de campo em geografia, questionamos até que ponto o problema residiria numa prática pedagógica de transposição da tradição da geografia científica para a realidade da escola, desconsiderando, muitas vezes, importantes variáveis envolvidas na sua realização pelo professor da Educação Básica e que interferem não só nos resultados como também nos próprios procedimentos a serem adotados. Mais do que colocar em xeque as lacunas a respeito da falta de uma reflexão e de um exame do próprio "campo" no seio da geografia, como advertiu Pires do Rio (2009), parece haver a necessária discussão a respeito das práticas educativas de geografia escolar, de forma a compreender essas lacunas em face do deslocamento, inter-relação, modificação e seleção presentes no movimento de tornar o trabalho de campo uma experiência educativa em geografia para alunos da Educação Básica.

\title{
Considerações finais
}

Gostaria de poder apontar, de forma sumária, alguns aspectos que considero relevantes nesse exercício a fim de provocar a abertura de diálogos sobre a questão:

1- Sobre o papel do aluno no campo: as experiências do trabalho de campo em geografia reservam ao aluno um papel de ilustre espectador, de receptáculo de um conhecimento que é "mostrado" no campo por meio da exposição do professor. Reduzem-se as possibilidades epistemológicas, metodológicas e pedagógicas de uma ferramenta que envolve esforço e investimento de recursos a uma prática que é, em essência, profundamente tradicional. Se a escola deve trabalhar com "problemas reais, concretos" bem como "por meio de solução de problemas" (OTT, 2012, p.67 e 69), então a solução desses problemas (ou dessas questões que merecem ser investigadas) envolve a mobilização de conhecimentos e de experiências pessoais dos alunos, sua participação, seu olhar inquisitivo. Não se reduz o papel do professor, mas muda-se a sua postura diante dos procedimentos didático-

7 Basil Bernstein, por sua vez, introduz nessa equação aquilo que chamava de "dispositivos pedagógicos", ou seja, as práticas pedagógicas que permitem que o conhecimento de uma disciplina ou campo específico possa ser "pedagogização" e vir a se constituir num conhecimento escolar, expresso no currículo e nos conteúdos. Na sua visão, dispositivo pedagógico fornece a "gramática intrínseca do discurso pedagógico" (SANTOS, 2003; MAINARDES, STREMEL, 2010). 
pedagógicos e de suas propostas de ensino, de forma a permitir a maior participação do aluno;

2- Sobre as formas de verificação da aprendizagem: A mudança no entendimento do papel do aluno no campo traz consigo a reavaliação das estratégias de verificação da aprendizagem. Estas não se confundem, estritamente, com a prova, mas se ampliam para o estabelecimento de procedimentos de verificação que incorporem a experiência e a relação com os conteúdos e os saberes incitados no/pelo campo. Questionamos até que ponto, por exemplo, há sentido no pedido de um "relatório" de campo a alunos em idade escolar. Por seu turno, se o campo suscitou a resolução de problemas, quais os elementos que compõem o problema que foram identificados pelos alunos? Que perspectivas de solução desses problemas são apresentadas? Como representar o campo e sua experiência por meio de outras linguagens como a fotografia, a música e as tecnologias e meios digitais?

3- Sobre o entendimento da natureza do campo e das possibilidades de efetivação na Educação Básica: Se partirmos da concepção preliminar de que o trabalho de campo é uma forma de pesquisa de dados feita de forma empírica por meio da observação e da investigação (LÈVY, LUSSAULT, 2003, p.904), caberia pensar nosso papel como professores na compreensão de como iniciar os estudantes nesse mistério. Ou seja, como criar mecanismos didáticos visando incorporar esses princípios da observação e da investigação na compreensão de problemas concretos na sua dimensão espacial-geográfica, com a mobilização dos alunos e a mediação didática do professor. Ora, o campo pode ser feito na própria comunidade, no bairro e na cidade do aluno. O que está em jogo não é a distância física, mas sim o procedimento em si e as possibilidades de aprendizagem dentro de uma perspectiva trans e multiescalar das inter-relações entre diferentes escalas geográficas de uma realidade contemporânea cada vez mais reticular (CAVALCANTI, 2010; SERPA, 2006). Na sua efetivação, o trabalho de campo não necessita eliminar o "passeio", a "visita", mas sim se abrir para outras possibilidades que exercitem no aluno a curiosidade, a autonomia e o prazer por aprender, individualmente ou em grupo.

O pano de fundo de tais observações, a propósito do trabalho de campo na geografia escolar é o papel fundamental da geografia como ciência e como disciplina escolar e, sobre isso, tem havido intenso esforço no sentido de validar os fundamentos da ciência geográfica, com sua "história, tradição e modo de trabalhar", como se referiu Michael Young ao defender o papel das disciplinas no currículo escolar (YOUNG, 2011, p. 617).

$\mathrm{Na}$ análise do trabalho de campo em geografia aqui empreendida pretendi discutir algumas questões que considero centrais: o papel e relevância do trabalho de campo na formação de geógrafos, as questões operacionais relativas ao planejamento, operacionalização e verificação/discussão da aprendizagem apreendidas por meio do campo num sentido mais amplo; a relação entre o conhecimento acadêmico e o escolar; a mediação didático-pedagógica imprescindiveis à implementação do trabalho de campo na Educação Básica. O texto foi, assim, um convite ao geógrafo e, principalmente, ao professor de geografia, a uma reflexão sobre a importância e os desafios dessa ferramenta voltada à pesquisa e ao ensino. 


\section{Referências}

ALENTEJANO, P. R. R. ROCHA-LEÃO, O. M. (2006) Trabalho de campo: uma ferramenta essencial para os geógrafos ou um instrumento banalizado? Boletim Paulista de Geografia - BPG, São Paulo, n 84, p. 51-67. Disponível em: https://www.agb.org.br/publicacoes/index.php/boletimpaulista/article/view/727/610 Acessado em: 11 de mar. 2020.

AZZI, S. (2002) Trabalho docente: autonomia didática e construção do saber pedagógico. In: PIMENTA, S. (Org.) Saberes pedagógicos e atividade docente. São Paulo: Cortez, p. 35-81.

BRASIL (2017) Ministério da Educação. Base Nacional Comum Curricular: a educação é a base. Brasilia: MEC.

Disponível em: http://portal.mec.gov.br/index.php?option=com_docman\&view=download\&alias=79601-anexotexto-bncc-reexportado-pdf-2\&category_slug=dezembro-2017-pdf\&ltemid=30192 Acessado em 17 mar. 2020.

BROOKS, C. (2019) A relação entre "expertise" da disciplina escolar e da ciência de referência. In: ROCHA, A. A.; MONTEIRO, A. M.; STRAFORINI, R. Conversas na escada: currículo, docência e disciplina escolar. Rio de Janeiro: Consequência, p. 143-165.

CARNEIRO, L. O. e. ali (2013) Territorialidades e Etnografia: Avanços metodológicos da análise geográfica de comunidades tradicionais. Ateliê Geográfico, Goiânia-GO, v. 7, n. 1, p.81-101. Disponível em: https://www.revistas.ufg.br/atelie/article/view/19824/13917 Acessado em: 19 jan. 2021.

CAVALCANTI, L. (1998) Geografia, escola e construção de conhecimentos. São Paulo: Papirus.

CAVALCANTI, L. (2006) Bases teórico-metodológicas da Geografia: uma referência para a formação e a prática de ensino. In. CAVALCANTI, L. (Org.). Formação de professores: concepções e práticas em geografia. Goiânia: Editora Vieira, p. 27-49.

CAVALCANTI, L. (2010) A geografia e a realidade escolar contemporânea: avanços, caminhos, alternativas. Anais... I SEMINÁRIO NACIONAL: CURRÍCULO EM MOVIMENTO - Perspectivas Atuais. Belo Horizonte, novembro de 2010. Disponivel em: http://portal.mec.gov.br/docman/dezembro2010-pdf/7167-3-3-geografia-realidade-escolar-lana-souza/file Acessado em: 17 mar. 2020.

CHARLOT, B. (2000) Da relação com o saber. Porto Alegre: Artes Médicas Sul.

CHARLOT, B. (2001) A noção de relação com o saber: base de apoio teórico e fundamentos antropológicos. In: CHARLOT, B. Os jovens e o saber: perspectivas mundiais. Porto Alegre: Artmed, p. 14-31.

CHARLOT, B. (2002) Formação de professores: a pesquisa e a política educacional. In: PIMENTA, S. G. GHEDIN, E. (Org.). Professor reflexivo no Brasil: gênese e crítica de um conceito. São Paulo: Cortez, p. 80-108.

CHEVALLARD, Y. (2000 [1991]). La transposición didáctica: del saber sabio al saber enseñado. Buenos Aires: Aique.

CLAVAL, P. (2013) O papel do trabalho de campo na geografia, das epistemologias da curiosidade às do desejo. Confins, n.17, p. 1-25. Disponível em: https://journals.openedition.org/confins/12414 Acessado em: 04 mar. 2020.

COCATO, G. P. (2019) O trabalho de campo enquanto experiência de ensino dos conteúdos de geografia urbana em um contexto escolar de precarização. Revista Brasileira de Educação em Geografia, Campinas, v. 9, n. 18, p. 185-210. Disponível em: http://www.revistaedugeo.com.br/ojs/index.php/revistaedugeo/article/view/652 Acessado em: 11 de mar. 2020.

COMPIANI, M.; CARNEIRO, C. D.R. (1993) Os papeis didáticos das excursões geológicas. Enseñança de las Ciencias de la Tierra (1.2), p. 90-98. 
DELYSER, D.; STARRS, P. (2001) Doing fieldwork: editors introduction. The American Geographical Society $91 \quad(1-2)$ : iv-viii. Disponível em: https://onlinelibrary.wiley.com/toc/19310846/2001/91/1\%E2\%80\%902 Acessado em: 11 mar. 2020. DRIVER, F. (2000) Editorial: Field-work in Geography. Transactions. Institute of British Geographers 25(3): 267-268. Disponível em: https://rgs-ibg.onlinelibrary.wiley.com/doi/pdf/10.1111/j.00202754.2000.00267.x Acessado em: 11 mar. 2020.

ENGLAND, K. R L. (1994) Getting Personal: Reflexivity, Positionality, and Feminist Research. The Professional Geographer 46 (1), p. 80-90. Disponível em: http://citeseerx.ist.psu.edu/viewdoc/download?doi=10.1.1.461.8298\&rep=rep1\&type=pdf Acessado em: 11 mar. 2020.

FORQUIN, J.C. (1996) As abordagens sociológicas do currículo: orientações teóricas e perspectivas de pesquisa. Educação e Realidade, Porto Alegre, 21(1), p.187-198.

GEOGRAPHICAL ASSOCIATION (2012) Thinking Geographically. 2012. Disponível em: http://www.geography.org.uk/download/GA_GINCConsultation12ThinkingGeographically.pdf Acessado em: 08 dez. 2015.

GOLLEDGE, R. G. (2002) The nature of geographic knowledge. Annals of the Association of American Geographers 92 (1):1-14. 2002. Disponível em: http://www.gvsu.edu/cms3/assets/B6FD1115-EC01A2A3-30867A2784081D10/TheNatureofGeographicalKnowledge.pdf Acessado em: 20 fev.2014.

GREGORY, et. al. (2009) The Dictionary of Human Geography. Cornwall: Wiley-Blackwell.

HERTAS, D. M. (2007) Além do aspecto puramente acadêmico: o trabalho de campo como uma verdadeira experiência de vida. GEOUSP - Espaço e Tempo, São Paulo, nº 21, p. 149 - 156. Disponível em: http://www.revistas.usp.br/geousp/article/view/74054/77696 Acessado em: 11 mar. 2020.

INTERNATIONAL GEOGRAPHICAL UNION - COMISSION ON GEOGRAPHICAL EDUCATION (IGUCGE). International Charter on Geographical Education. Disponível em: https://www.igu-cge.org/wpcontent/uploads/2019/03/IGU_2016_eng_ver25Feb2019.pdf Acessado em: 10 mar. 2020.

JOHNSTON, R.; SIDAWAY, J. D. (2016) Feminist Geography. In Geography \& geographers: AngloAmerican human geography since 1945. Nova York: Routledge, p.281-307.

KATZ, C. (1994) Playing the field: questions of fieldwork in geography. Professional Geographer, Volume 46, Number 1, p. 67-72. Disponível em: https://onlinelibrary.wiley.com/doi/abs/10.1111/j.0033-0124.1994.00067.x Acessado em: 11 mar. 2020.

KENT, M. et. al. (1997) Fieldwork in Geography Teaching: a critical review of the literature and approaches Journal of Geography in Higher Education, vol. 21, n.․ 3, p. 313- 332. Disponível em: https://www.researchgate.net/publication/236631524_Fieldwork_in_geography_teaching_a_critical_ review_of_literature_and_approaches Acessado em: 17 mar. 2020.

LACOSTE, Y. (2006[1977]) A pesquisa e o trabalho de campo: um problema político para os pesquisadores, estudantes e cidadãos. Boletim Paulista de Geografia, São Paulo, nº 84, p. 77-92. Disponível em: https://www.agb.org.br/publicacoes/index.php/boletim-paulista/article/view/729 Acessado em: 17 mar. 2020.

LEGENDRE, M.-F. (1994) Problématique de l'apprentissage et de l'enseignement des sciences au secondaire: un état de la question. Revue des sciences de l'éducation, 20 (4), 657-677. Disponível em: https://www.erudit.org/fr/revues/rse/1994-v20-n4-rse1853/031761ar.pdf Acessado em: 11 mar.2020.

LÉVY, J.; LUSSAULT, M. (Dir.) (2003) Dictionnaire de la géographie et de l'espace des sociétés, Paris: Belin.

LOPES, A. C. (1999) Conhecimento escolar: ciência e cotidiano. Rio de Janeiro: EdUERJ. 
LOPES, A.C. (1997) Conhecimento escolar: processos de seleção cultural e de mediação didática. Educação e Realidade, Porto Alegre, 22(1), p. 95-112.

LOZANO, G. S. (2016) Etnografia: um Método para Observar a Fronteira. Perspectiva Geográfica, Marechal Cândido Rondon, Ed. Esp., v.11, n.15, p. 279-284. Disponível em: http://erevista.unioeste.br/index.php/pgeografica/article/view/17027/11338 Acessado em: 18 mar. 2020. MAIA, D.S. (1997) Os escritos etnográficos e a Geografia: encontros e desencontros. GEOUSP Espaço e Tempo, 1(2), p. 21-29. Disponível em: http://www.revistas.usp.br/geousp/article/view/123236 Acessado em: 18 mar.2020.

MAINARDES, J. (2006) Abordagem do ciclo de políticas: uma contribuição para a análise de políticas educacionais. Educ. Soc., Campinas, vol. 27, n. 94, p. 47-69.

MAINARDES, J. STREMEL, S. (2010) A teoria de Basil Bernstein e algumas de suas contribuições para as pesquisas sobre políticas educacionais e curriculares. Revista Teias, v. 11, n. 22, p. 31-54. Disponível em: https://www.e-publicacoes.uerj.br/index.php/revistateias/article/view/24114/17092 Acessado em: 12 mar. 2020.

MCSWEENEY, K.; WINKLERPRINS, A. (2020) Introduction to the Special Issue: Fieldwork in the $21^{\text {ST }}$ st Century, Geographical Review, 110:1-2,1-7. Disponível em: https://www.tandfonline.com/doi/pdf/10.1080/00167428.2019.1689361?needAccess=true Acessado em: 11 mar. 2020.

NAST, Heidi J. (1994) Opening remarks on "women in the field" Professional Geographer, Volume 46, Number 1 1, p. 54-66. Disponível em: https://www.researchgate.net/publication/248463024_Women_in_the_Field_Critical_Feminist_Meth odologies_and_Theoretical_Perspectives Acessado em: 11 mar. 2020.

OTT, M. B. (2012) Ensino por meio de solução de problemas. In: CANDAU, V. L. (Org.). A didática em questao. Petrópolis: Vozes, p.66-75.

PÉREZ, F.F.G. (2018) La enseñanza de la geografía y sus posibilidades em el currículum. In TONINI et. al. O ensino de geografia e suas composições curriculares. Porto Alegre: Mediação, p. 9-20.

PIRES DO RIO, G. A. (2011) Trabalho de campo na (re) construção da pesquisa geográfica: reflexões sobre um tradicional instrumento de investigação. GEOgraphia, Niterói, p. 42-58. Disponível em: https://periodicos.uff.br/geographia/article/view/13615/8815 Acessado em: 11 mar. 2020.

PONTUSCHKA, N. N. et. al (1991) O "estudo do meio" como trabalho integrador das práticas de ensino. Boletim Paulista de Geografia, São Paulo, n. ${ }^{\circ} 70$, p. 45-52.

PRESTON, L. (2016) Field 'Work' Vs 'Feel' Trip: Approaches to Out -of-Class Experiences in Geography Education. Geographical Education, volume 29, p. 9-22. Disponível em: https://files.eric.ed.gov/fulltext/EJ1123180.pdf Acessado em: 11 mar. 2020.

QUINTANEIRO, T. et al. (2000) Max Weber. In Um toque de clássicos: Durkheim, Marx e Weber. Belo Horizonte: Editora UFMG, p. 104-147.

RICHTER, D. et al. (2012) The sketch maps as a language to analyze geographic reasoning. Procedia - Social and Behavioral Sciences n. 46 p. 5183 - 5186. Disponível em https://www.researchgate.net/publication/275541945_The_Sketch_Maps_as_a_Language_to_Analy ze_Geographic_Reasoning Acessado em: 11 mar. 2020.

RODRIGUES, A. B.; OTAVIANO, C. A. (2001) Guia Metodológico de Trabalho de Campo em Geografia. Geografia, Londrina, v. 10, n. 1, p. 35-43. Disponível em: http://www.uel.br/revistas/uel/index.php/geografia/article/view/10213 Acessado em: 17 mar. 2020. RUELLAN, F. (1994) O trabalho de campo nas pesquisas originais de geografia regional. Revista Brasileira de Geografia. , v. 56, n. 1/4, pp. 35-50. Disponível em: 
https://biblioteca.ibge.gov.br/visualizacao/periodicos/115/rbg_1994_v56_n1_n4.pdf Acesso em: 11 mar. 2020.

SANDERS, R. (2007) Developing Geographers through Photography: Enlarging Concepts. Journal of Geography in Higher Education, vol. 31, $n^{\circ}$. 1, 181-195. Disponível em: http://citeseerx.ist.psu.edu/viewdoc/download?doi=10.1.1.553.2842\&rep=rep1\&type=pdf Acessado em 11 mar. 2020.

SANTOS, L. L. C. P. (2003) Bernstein e o campo educacional: relevância, influências e incompreensões. Cadernos de Pesquisa, Vitória, n. 120, p. 15-49. Disponível em: http://www.scielo.br/pdf/cp/n120/a04n120.pdf Acessado em: 12 mar. 2020.

SAUER, Carl O. (1956) The Education of a Geographer. Annals of the Association of American Geographers, Vol. 46, No. 3, p. 287-299. Disponível em: http://www.appstate.edu/ perrylb/Courses/5000/Readings/Sauer_1956.pdf Acessado em: 11 mar. 2020.

SERPA, A. (2006) O trabalho de campo em geografia: uma abordagem teórico-metodológica. Boletim Paulista de Geografia, São Paulo, no 84, p. 7-24. Disponível em: http://www.uel.br/cce/geo/didatico/omar/pesquisa_geografia_fisica/BPG84_Pesquisa.pdf Acessado em: 18 mar.2020.

SILVA, J. B. (2012) França e escola brasileira de geografia: verso e reverso. Fortaleza: Edições UFC. SILVA, J. M. (2010) Geografias Feministas, sexualidades e corporalidades: desafios às práticas investigativas da ciência geográfica. Espaço e Cultura, UERJ, RJ, n. 27, p. 39-55. Disponível em: https://www.e-publicacoes.uerj.br/index.php/espacoecultura/article/viewFile/3542/2464 Acessado em: 17 mar. 2020.

SILVA, J. M. (2016) Contribuições das Geografias Feministas nas abordagens das relações entre espaço e diferenças. In: SPOSITO, E. S et al. (Org.) (2016) A diversidade da Geografia Brasileira: escalas e dimensões da análise e da ação. Rio de Janeiro: Consequência, p.507-522.

SOUZA, S. O.; CHIAPETTI, R. J. N. (2012) O trabalho de campo como estratégia no ensino em geografia. Revista de Ensino de Geografia, Uberlândia, v. 3, n. 4, p. 3-22. Disponível em: http://www.revistaensinogeografia.ig.ufu.br/N.4/Art1v3n4.pdf Acessado em: 11 mar. 2020.

STENGEL, B. S. (1997) 'Academic discipline' and 'school subject': Contestable curricular concepts. Journal of Curriculum Studies, 29:5, 585-602. Disponível em: https://www.researchgate.net/publication/238399007_'Academic_discipline'_and_'school_subject'_ Contestable_curricular_concepts\#fullTextFileContent Acessado em: 17 mar. 2020.

STRAFORNI, R. (2004) Ensinar geografia: o desafio da totalidade-mundo nas séries iniciais. São Paulo: Annablume.

SUNDBERG, J. (2003) Masculinist Epistemologies and the Politics of Fieldwork in Latin Americanist Geography. The Professional Geographer, 55(2) p.180-190. Disponivel em: https://www.academia.edu/2967794/Masculinist_Epistemologies_and_the_Politics_of_Fieldwork_in _Latin_Americanist_Geography Acessado em 11 mar. 2020.

TRICART, J. (2017 [1977]) O campo na dialética da geografia. Geousp - Espaço e Tempo v. 21, n. 1, p. 305-314. Disponível em: https://www.revistas.usp.br/geousp/article/view/125762/132450 Acessado em: 11 mar. 2020.

TUAN, Y.F. (2001) Life as a field trip. The Geographical Review, v 9 (1-2), p. 41-45. Disponível em: https://onlinelibrary.wiley.com/doi/10.1111/j.1931-0846.2001.tb00456.x Acessado em: 17 mar. 2020.

VADJUNEC, J. M. (2020) A Place for Serendipitous Mistakes? Selling Mixed Methods Fieldwork to Students in a Digital Age, Geographical Review, 110:1-2, 23-37. 
VYGOTSKY, L. S. (1989) Pensamento e linguagem. São Paulo: Martins Fontes.

VYGOTSKY, L.S. (1998) A formação social da mente. São Paulo: Martins Fontes.

YOUNG, M. F. D. O (2011) Futuro da educação em uma sociedade de conhecimento: o argumento radical em defesa de um currículo centrado em disciplinas. Revista Brasileira de Educação, São Paulo, v. 16, n. 48, p. 609-623. Disponível em: http://www.scielo.br/pdf/rbedu/v16n48/v16n48a05.pdf Acessado em: 15 mar. 2020. 